\title{
THE INCIDENCE OF INTESTINAL PARASITES AMONG CHILDREN IN HIVI PEDIATRIC HOSPITAL, DUHOK, IRAQ.
}

\author{
Jehan Nori Hussein ${ }^{\mathrm{a}, *}$ and Azad Abdullah Meerkhan ${ }^{\mathrm{b}}$ \\ ${ }^{a}$ Department of Pharmacy, Duhok Technical Institute, Duhok Polytechnic University, Kurdistan Region, Iraq (jehannoori@yahoo.com) \\ ${ }^{\mathrm{b}}$ Department of Nursing, Duhok Technical Institute, Duhok Polytechnic University, Kurdistan Region, Iraq (azad.meerkhan@dpu.edu.krd)
}

Received: Jan. 2019 / Accepted: Mar., 2019 / Published: Mar., 2019

https://doi.org/10.25271/siuoz.2019.7.1.571

\begin{abstract}
:
This study has conducted in Hivi Pediatric Hospital, Duhok Province, Iraq, to estimate the gastrointestinal parasites infection among patients contacted this hospital. Overall patients, $22.27 \%(261 / 1,172)$ were diagnosed as infected by parasites; more of them were from summer season with the infection rate of $24.83 \%(216 / 870)$ versus $14.90 \%(45 / 302)$ in autumn, rural residence had a greater rate of infection $65.90 \%(172 / 261)$ as compared with urban residence 34.09 (89/261), males were more infected than females $(63.98 \%$ versus $36.02 \%$ respectively), the age group of three years and less had the highest rate of infection, while the age group of more than 9 years had the lowest rate $(57.85 \%, 4.98 \%$ respectively). Concerning the children feeding way, the artificially feeding had the highest rate then mixed feeding and Breastfeeding $(58.16 \%$, $25.53 \%$ and $16.31 \%$ respectively). As general, the infection with protozoa (84.67) was higher than helminthes (18.01\%) with some cases of infection by both of protozoa and helminthes (4.98). Regarding each parasite separately, Entamoeba histolytica had the highest infection rate then Giardia lamblia., Enterobius vermicularis, Cryptosporidium Spp., Entamoeba coli and Blastocystis hominis (38.70\%, 25.67\%, 18.01, $9.20 \%, 6.51$ and 4.60 respectively).
\end{abstract}

KEYWORDS: Children Infection, Protozoa, Helminthes, Parasitic Infection, Gastrointestinal Infection.

\section{INTRODUCTION}

Gastrointestinal parasites (GP) contribute significantly to global levels of morbidity and mortality. The World Health Organization (WHO) estimates that over two billion people in the world are infected with at least one form of parasites [1].

Gastrointestinal parasites cause intestinal parasitosis (IP), are infectious diseases of poverty and considered as a public health problem still found in North America and Europe, their prevalence is highest in areas of intense poverty in low- and middle-income; developing, underdeveloped, tropical and subtropical countries and in areas of poor hygiene [1-4]. Human gastrointestinal tract parasites can be largely categorized into two groups, protozoa and helminths. The soil-transmitted helminths (Ascaris lumbricoides, hookworm and Trichuris trichiura) are the most prevalent, infecting an estimated one-sixth of the global population [5]. On another hand, Gastrointestinal parasites may affect one fourth of the global population of all ages and both sexes, mainly due to fecal contamination of food and water $[6,7]$. It causes undernourishment, morbidity and incapacitation due to their behavior particularly in children [8].

Intestinal parasitosis is common studied in children, neglecting the adults that are also at high risk and source of transmission $[5,6]$. To date, the study of intestinal parasites and chronic gastrointestinal disorders has been limited predominately to Giardia lamblia. Specifically, in the 12-30 months following a waterborne disease outbreak due to an acute Giardia infection, $80.5 \%$ of infected individuals had symptoms and $24.3 \%$ had functional dyspepsia [9]. The prevalence of IP varies according to weather, sanitation, social and economic factors $[10,11]$. The mortality rate from IP is low, however, the morbidity can be high, and thus it implies high healthcare costs [12]. It is associated to intestinal malabsorption, abdominal pain, diarrhea, lower growth and labor incapacity [13]. Gastrointestinal parasites primarily affect children in disfavored settings with limited or no access to safe drinking water, inadequate sanitation, and substandard housing where poor hygiene practices are common [5]. Because enteric nematodes, cestodes, trematodes and protozoans often occur simultaneously in endemic areas, polyparasitism has been suggested to have a synergistic effect in exacerbating detrimental health outcomes in infected individuals [14].

Thus, IP have been linked to malabsorption, malnutrition, stunting, chronic anemia, cognitive impairment and failure to thrive [15-18]. Despite their unquestionable socio-economic and public health impact [3], the epidemiology of GP is still poorly understood in many regions of the world and only partially addressed in the Global Burden of Disease studies (GBD) [19].

The greatest obstacle to effective control of parasites in at-risk populations is inadequate knowledge of the geographical distribution of infection and the demographic variables that influence the prevalence of infection [2].

Enteric protozoans Cryptosporidium spp., Giardia intestinalis and Blastocystis spp., together with Entamoeba histolytica, are regarded as the most common and important causes of protozoan-diarrhoeal disease in humans globally. These parasites are transmitted directly by contacts with infected persons or animals or indirectly through ingestion of contaminated water or food. Only in developing countries, about 200 million people are estimated to have symptomatic giardiasis [20], whereas cryptosporidiosis is a leading cause of diarrheal death in children younger than 5 years globally, only second after rotaviral enteritis [21]. Regarding Blastocystis spp. it is currently estimated that up to 1 billion humans across the world would be colonized/infected with these protozoan species [22]. Although the clinical significance of Blastocystis spp. is still the focus of intense debate, there is mounting in vitro and in vivo evidence linking the presence of these protozoan species with intestinal (nausea, anorexia, flatulence, acute or chronic diarrhea, irritable bowel syndrome) and extra-intestinal (urticarial) disorders $[23,24]$. Moreover, invasive and inflammatory potential of the parasites has also been reported [25].

\footnotetext{
* Corresponding author

This is an open access under a CC BY-NC-SA 4.0 license (https://creativecommons.org/licenses/by-nc-sa/4.0/)
} 
The incidence of protozoa and helminthes varies with different geographical location [26]. Therefore this study aimed to study the incidence of intestinal parasites and determining their relation to sex, age, residence and feeding type of children.

\section{MATERIALS AND METHODS}

\subsection{Description of the study area}

This prospective study was conducted from the beginning of Duhok summer to the end of its autumn of the year 2018 (from June 2018 to November) [27] in Hivi Pediatric Hospital, Duhok, Kurdistan Region, Iraq.

\subsection{Planning and sample collection}

Children visited Hivi Pediatric Hospital during above period that between ages of 1 month - 12 years who presented with gastrointestinal symptoms were investigated for intestinal parasitic infection. Children above 12 years old and children below 12 without gastrointestinal symptoms were excluded from this study. This study was approved by Duhok Health Directorate ethical committee, permission was obtained from parents, and questionnaire was designed to obtain the demographic data, socioeconomic conditions. The stool samples of children were given a labeled, leak proof container with a plastic scoop (Hi-media) to collect sample as per the standard procedure of the WHO and processed within 4 hours of collection. All the stool samples were examined by the direct microscopic examination and by the formalin-ether concentration methods. Samples for which identification of parasites was difficult or uncertain were stained with an iodine solution ( $1 \% \mathrm{I} 2$ and $2 \% \mathrm{KI})$ and used Modified ZiehlNeelsen Stain to facilitate analysis [26]. A trained parasitologist screened the slides for eggs of parasites and the results were recorded on an Excel spreadsheet.

\subsection{Data analysis}

The incidence of the parasites was calculated according to children residency, sex, age and dietary habit, analysis of variance was assessed to compare several groups using chi- square test and ANOVA, P. value of $<0.05$ was considered indicative of a statistically significant difference. All statistical tests were performed using SPSS 19 software.

\section{RESULTS AND DISCUSSION}

\subsection{The distribution of GP over season and monthes}

From a total of 1,172 children visited Hivi Pediatric hospital, the overall infection rate was $22.27 \%$, while in both summer and autumn seasons the GP infection rates were $24.83 \%$ and $14.90 \%$ respectively. With respect to studied months (June, July, August, September, October and November) the infection rates were $23.14 \%, \quad 24.76 \%, 26.32 \%, \quad 16.53 \%, \quad 14.13 \%$ and $13.48 \%$ respectively, with the highest rate in August (Table 1).

Table 1. The Number of Visitors and Infection Rates Distributed on Seasons and Months

\begin{tabular}{|c|c|c|c|c|c|}
\hline Season & Month & Cases & Negative & Positive & $\begin{array}{c}\text { Infectio } \\
\text { n Rates }\end{array}$ \\
\hline \multirow{4}{*}{ Summer } & June & 255 & 196 & 59 & 23.14 \\
\cline { 2 - 6 } & July & 311 & 234 & 77 & 24.76 \\
\cline { 2 - 6 } & August & 304 & 224 & 80 & 26.32 \\
\cline { 2 - 6 } & Total & $\mathbf{8 7 0}$ & $\mathbf{6 5 4}$ & $\mathbf{2 1 6}$ & $\mathbf{2 4 . 8 3}$ \\
\hline \multirow{4}{*}{ Autumn } & September & 121 & 101 & 20 & 16.53 \\
\cline { 2 - 6 } & October & 92 & 79 & 13 & 14.13 \\
\cline { 2 - 6 } & November & 89 & 77 & 12 & 13.48 \\
\cline { 2 - 6 } & Total & $\mathbf{3 0 2}$ & $\mathbf{2 5 7}$ & $\mathbf{4 5}$ & $\mathbf{1 4 . 9 0}$ \\
\hline \multicolumn{2}{|c|}{ Grand Total } & $\mathbf{1 1 7 2}$ & $\mathbf{9 1 1}$ & $\mathbf{2 6 1}$ & $\mathbf{2 2 . 2 7}$ \\
\hline
\end{tabular}

The results above are in agreement with Amin [28] in his study on some patients in District of Columbia, USA, which recorded the lowest prevalence in winter (22-27\%), gradually increased during the spring, reached peaks between July and October (36-43\%, and gradually decreased to $32 \%$ in December.

\subsection{The rate of GP infection distribution over the children residency}

In both rural and urban (as a residency of visitors), the rate of infection rate in rural residency was higher than urban residency $25.26 \%(172 / 681)$ and $18.13 \%(89 / 491)$ respectively (Table 2).

Table 2. Number of children and Infection Rates Distributed on Recidency of children

\begin{tabular}{|c|c|c|c|}
\hline \multirow{2}{*}{ Residence } & \multirow{2}{*}{$\begin{array}{c}\text { No. of } \\
\text { children }\end{array}$} & \multicolumn{2}{|c|}{ Infected children } \\
\cline { 3 - 4 } & & No. & \% \\
\hline Urban & 491 & 89 & 18.13 \\
\hline Rural & 681 & 172 & 25.26 \\
\hline Total & $\mathbf{1 1 7 2}$ & $\mathbf{2 6 1}$ & $\mathbf{2 2 . 2 7}$ \\
\hline
\end{tabular}

When the both rates compared together, it has been found that rural and urban rates were $65.91 \%(172 / 261)$ and $34.09 \%(89 / 261)$ respectively (Table 2 ), this deference was statistically significant at P. $<0.05$.

\subsection{The rate of GP infection distribution over the sex and age}

The infection rates of GP in both males and females are shown in table 3, which indicates that males have the highest rate than females $(63.98 \%(167 / 261)$ and 36.02 (94/261) respectively). This means that the sex of the child is an important factor affecting the rate of infection, this agreed with the studies conducted by Ali, Duhok DMaS [2, 29] in Duhok city; [3] in Ramadi city and in Gaza [4]. The higher rates of infection among males children may be their higher activities and more contact with the environmental conditions than females. Within groups of ages also, males were more infected than females in all groups except the group More than 9 to 12 years old, that showed a dominance of females over males $(53.85(7 / 13)$ verses $46.15 \%(6 / 13)$, this may be due to the household activities (Table 3 ).

Table 3. The Gastrointestinal Parasites Infection Rates according to Sexes and Ages

\begin{tabular}{|c|c|c|c|c|c|c|}
\hline \multirow{2}{*}{ Age (Years) } & \multirow{2}{*}{$\%$} & \multicolumn{2}{|c|}{ Female } & \multicolumn{2}{c|}{ Male } & \multirow{2}{*}{ Total } \\
\cline { 3 - 6 } & & No. & $\%$ & No. & $\%$ & \\
\hline$<=3$ years & 57.85 & 54 & 35.76 & 97 & 64.24 & 151 \\
\hline$>3-6$ & 30.27 & 31 & 39.24 & 48 & 60.76 & 79 \\
\hline$>6-9$ & 6.90 & 2 & 11.11 & 16 & 88.89 & 18 \\
\hline$>9-12$ & 4.98 & 7 & 53.85 & 6 & 46.15 & 13 \\
\hline \multicolumn{2}{|c|}{ Total } & $\mathbf{9 4}$ & $\mathbf{3 6 . 0 2}$ & $\mathbf{1 6 7}$ & $\mathbf{6 3 . 9 8}$ & $\mathbf{2 6 1}$ \\
\hline
\end{tabular}

On the other hand, the GP infection rate was the highest in the group of three years and less $(57.85 \%(151 / 261))$, and the rate was decreased by increasing of age (More than 3 to 6 Years: $30.27 \%$ (79/261), More than 6 to 9 Years: $6.90 \%$ (18/261), More than 9 to 12 Years: $4.98 \%$ (13/261)) (Table 3). These rates were higher than that reported by Al Saeed and Issa [29] in Duhok city who found infection rates of $50.2 \%$ in children of ages closer to the ages selected in this study (group 1 to 3 years). This may be due to the increased exposure to infection by contaminated food or their low immunity which makes them more susceptible to infection, $[4,9]$ while these rates were lower than reported by Al Saeed and Issa [29] who reported $40.4 \%$ of the age group 4 to 6 years. Then an inverse relationship was observed between infection rate and age since the rate of infection was decreased with the increasing of age, the lowest rate of infection (4.9.8\%) appeared in the age group more than 9 to 12 years old, this may be due to practicing more hygienic habits. This result disagreed with high rate $81.2 \%$ in children of ages 10 to 12 years reported by Al Saeed and Issa [29]. 
3.4 The rate of GP infection according to the dietary habit or feeding way/s.

The rates of infected children according to the feeding way were explained declared in the figure 1 , which shown that children fed artificially had highest rate followed by mixed way (artificial feeders + breast feeders) then breast feeders $(58.16 \%(82 / 141)$, $25.53 \%(36 / 141)$ and $16.31 \%(23 / 141)$, respectively as shown in figure 1). This may be interpreted by milk bottles contamination in artificial feeders [4].

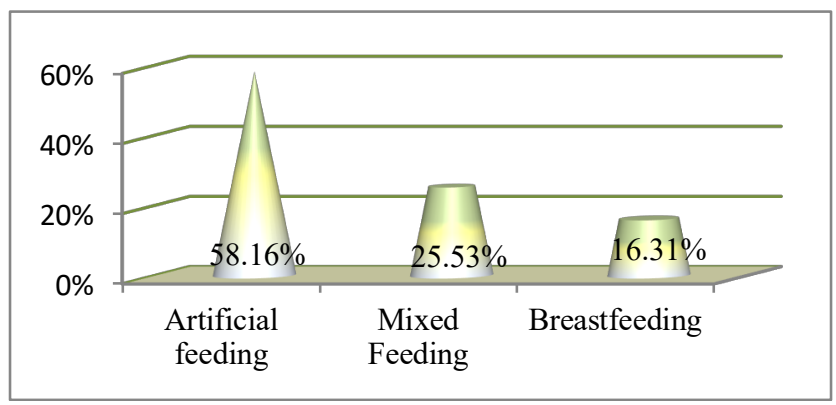

Fig. 1. The gastrointestinal parasites infection rates according to dietary habit or feeding way/s.

\subsection{The rate of infection of the parasites that causes GP in examined children.}

All parasites found in this study were belonging to two main Phyla including protozoa and helminthes. The number of cases and infection rates were shown in the table 4 , which declared that protozoa had a significant dominancy on helminthes $(84.67 \%$ $(221 / 261)$ and $18.01 \%(47 / 261)$ respectively). This is in agreement with Ahmad [30] in Erbil city in who recorded a higher rate 37.12\% with protozoa as compared with helminthes $3.03 \%$. [3], in Ramadi and Falluja cities he reported a higher rate $43.62 \%$ with protozoa in comparison with helminthes $5.74 \%$, but this study disagreed with that observed by Hama [31] who reported a slightly lower rate $18.28 \%$ with protozoa as compared with helminthes $19.16 \%$. It is noteworthy to mention that all helminthes found were Enterobius vermicularis nematodes. Could be due to the methods of diagnosis used in this study, this variation is not significant at all and may reflected that direct smear methods are less sensitive and required triplicate successive examination which is not applied here and that referred previously by others [32].

Table 4. the gastrointestinal parasites infection rates according to seasons and group of parasites

\begin{tabular}{|c|c|c|c|c|c|c|c|c|}
\hline \multirow{2}{*}{ Season } & \multirow{2}{*}{ Month } & \multirow{2}{*}{ Infected } & \multicolumn{2}{c|}{ Protozoa } & \multicolumn{2}{c|}{ Helminthes } & \multicolumn{2}{c|}{ Mixed } \\
\cline { 4 - 9 } & & & No. & $\mathbf{\%}$ & No. & \% & No. & \% \\
\hline \multirow{4}{*}{ Summer } & June & 59 & 49 & 83.05 & 12 & 20.34 & 2 & 3.39 \\
\cline { 2 - 9 } & July & 77 & 65 & 84.42 & 15 & 19.48 & 3 & 3.90 \\
\cline { 2 - 9 } & August & 80 & 64 & 80.00 & 15 & 18.75 & 5 & 6.25 \\
\cline { 2 - 9 } & Total & $\mathbf{2 1 6}$ & $\mathbf{1 7 8}$ & $\mathbf{8 2 . 4 1}$ & $\mathbf{4 2}$ & $\mathbf{1 9 . 4 4}$ & $\mathbf{1 0}$ & $\mathbf{4 . 6 3}$ \\
\hline \multirow{5}{*}{ Autumn } & September & 20 & 18 & 90.00 & 2 & 10.00 & 0 & 0.00 \\
\cline { 2 - 9 } & October & 13 & 13 & 100 & 1 & 7.69 & 1 & 7.69 \\
\cline { 2 - 9 } & November & 12 & 12 & 100 & 2 & 16.67 & 2 & 16.67 \\
\cline { 2 - 9 } & Total & $\mathbf{4 5}$ & $\mathbf{4 3}$ & $\mathbf{9 5 . 5 6}$ & $\mathbf{5}$ & $\mathbf{1 1 . 1 1}$ & $\mathbf{3}$ & $\mathbf{6 . 6 7}$ \\
\hline \multicolumn{2}{|c|}{ Grand Total } & $\mathbf{2 6 1}$ & $\mathbf{2 2 1}$ & $\mathbf{8 4 . 6 7}$ & $\mathbf{4 7}$ & $\mathbf{1 8 . 0 1}$ & $\mathbf{1 3}$ & $\mathbf{4 . 9 8}$ \\
\hline
\end{tabular}

With respect to each parasite separately, this study found that Entamoeba histolytica had the more frequency among all species and recorded an infection rate $38.70 \%$ (101/261). folowed by Giardia lamblia, Enterobius vermicularis, Cryptosporidium Spp., Entamoeba coli and Blastocystis hominis (25.67\% (67/261), $18.01 \%(47 / 261) 9.20 \%(24 / 261), 6.51 \%(17 / 261)$ and $4.60 \%$ $(12 / 261)$ respectivly) as shown in table 5. This hight rate of infection with Entamoeba histolytica was higher than in other studies performed in Kurdistan region such as Ali [7] who reported $31.6 \%$ in Kalar town, Sulaimani city, Ahmed [30] recorded a rate of $12.95 \%$ in Erbil city, Hawezy [10], also recorded rate $13.4 \%$ among children in Erbil city. The rate of infection with Giardia lamblia $25.67 \%$ reported in this study was lower than that reported by Al Saeed and Issa [29] among children in Duhok city who recorded rate $38.5 \%$, while this rate was higher than that reported by AlKhalefawi [3] from children in Ramadi and Falluja cities, Ahmed 13.8\%, [30] from children in Erbil city and Hama [31] among primary school in Erbil city they recorded rates $14.02 \%$ and $13.3 \%$ respectively.

Table 5. The Gastrointestinal Parasites Infection Rates according to season, months and species of parasites

\begin{tabular}{|c|c|c|c|c|c|c|c|c|c|}
\hline Season & Month & & G & Eh & Ec & Bh & Cs & Ev & Total \\
\hline \multirow{8}{*}{ Summer } & \multirow{2}{*}{ June } & No. & 13 & 24 & 4 & 3 & 5 & 12 & \multirow{2}{*}{59} \\
\hline & & $\%$ & 22.03 & 40.68 & 6.78 & 5.08 & 8.47 & 20.34 & \\
\hline & \multirow{2}{*}{ July } & No. & 11 & 33 & 5 & 6 & 10 & 15 & \multirow{2}{*}{77} \\
\hline & & $\%$ & 14.29 & 42.86 & 6.49 & 7.79 & 12.99 & 19.48 & \\
\hline & \multirow{2}{*}{ August } & No. & 19 & 35 & 2 & 3 & 5 & 15 & \multirow{2}{*}{80} \\
\hline & & $\%$ & 23.75 & 43.75 & 2.50 & 3.75 & 6.25 & 18.75 & \\
\hline & \multirow{2}{*}{ Total } & No. & 43 & 92 & 11 & 12 & 20 & 42 & \multirow{2}{*}{216} \\
\hline & & $\%$ & 19.91 & 42.59 & 5.09 & 5.56 & 9.26 & 19.44 & \\
\hline \multirow{8}{*}{ Autumn } & \multirow{2}{*}{ September } & No. & 9 & 3 & 2 & 0 & 4 & 2 & \multirow{2}{*}{20} \\
\hline & & $\%$ & 45.00 & 15.00 & 10.00 & 0.00 & 20.00 & 10.00 & \\
\hline & \multirow{2}{*}{ October } & No. & 8 & 3 & 2 & 0 & 0 & 1 & \multirow{2}{*}{13} \\
\hline & & $\%$ & 61.54 & 23.08 & 15.38 & 0.00 & 0.00 & 7.69 & \\
\hline & \multirow{2}{*}{ November } & No. & 7 & 3 & 2 & 0 & 0 & 2 & \multirow{2}{*}{12} \\
\hline & & $\%$ & 58.33 & 25.00 & 16.67 & 0.00 & 0.00 & 16.67 & \\
\hline & \multirow{2}{*}{ Total } & No. & 24 & 9 & 6 & 0 & 4 & 5 & \multirow{2}{*}{45} \\
\hline & & $\%$ & 53.33 & 20.00 & 13.33 & 0.00 & 8.89 & 11.11 & \\
\hline \multirow{2}{*}{\multicolumn{2}{|c|}{ Grand Total }} & No. & 67 & 101 & 17 & 12 & 24 & 47 & \multirow{2}{*}{261} \\
\hline & & $\%$ & 25.67 & 38.70 & 6.51 & 4.60 & 9.20 & 18.01 & \\
\hline
\end{tabular}

$\mathrm{G}=$ Giardia lamblia $\mathrm{Eh}=$ Entamoeba histolytica $\mathrm{Ec}=$ Entamoeba coli

$\mathrm{Bh}=$ Blastocystis hominis $\mathrm{Cs}=$ Cryptosporidium Spp $. \mathrm{Ev}=$ Enterobius vermicularis

\section{ACKNOWLEDGMENT}

We are thankful to Hivi Pediatric Hospital and its entire staff for assistance in obtaining data and stool samples.

\section{REFERENCES}

[1] WHO. (World Health Organization), Report of the Third Global Meeting of the Partners for Parasite Control: Deworming for health and development. Third Global Meeting of the Partners for Paratise Control: WHO; 2005.

[2] Mero WM, Hussein JN. Prevalence of Intestinal Parasites Among Children in Various Localities of Duhok City and Nearby Villages. Science Journal of University of Zakho 2013;1:189.

[3] Al-Khalefawi MJM. Study on the parasites of digestive canal of children under five years and their effects on some blood parameters. M.Sc. Thesis.College of Science. University of Al Mustansirya; 2006.

[4] Al-Hindi AI, El-Kichaoi AY. Occurrence of gastrointestinal parasites among pre-school children, Gaza, Palestine. IUG Journal of Natural Studies 2015;16.

[5] Harhay MO, Horton J, Olliaro PL. Epidemiology and control of human gastrointestinal parasites in children. Expert review of antiinfective therapy $2010 ; 8: 219$.

[6] Carvajal-Restrepo H, Orrego-Morales C, Vega-Orrego T, ArangoArango S, Buitrago-Agudelo D, Maya-Betancourt MC, et al. Screening for intestinal parasites in adults from three different regions of Colombia. Infectio 2018;23:33.

[7] Mohammad-Ali, S. M. Prevalence of Giardia lamblia and Entamoeba histolytica in infected children in Kalar town with some serological and biochemical parameters. M.Sc. thesis, college of science, Sulaimani university-Sulaimani, 2009.

[8] Dhanabal J, Selvadoss PP, Muthuswamy K. Comparative study of the prevalence of intestinal parasites in low socioeconomic areas from South Chennai, Indian Journal of parasitology research $2014 ; 2014$.

[9] Develoux M, Alarou A, Mouchet F. High prevalence of giardiasis in an urban population in Niger. The Journal of tropical medicine and hygiene 1990;93:355.

[10] Hawezy A. The causes of diarrhoea among children in Erbil district. M. Sc. Thesis, College of Medicine, University of Duhok; 2000 . 
[11] Miranda JAN. Prevalencia de parasitosis interstinales en unidades eduativas de Ciudad Bolivar, Venezuela. Revista Cuidarte 2015;6:1076.

[12] Organization WH. Prevention and control of intestinal parasitic infections: report of a WHO Expert Committee [meeting held in Geneva from 3 to 7 March 1986]. 1987.

[13] van Lieshout L, Roestenberg M. Clinical consequences of new diagnostic tools for intestinal parasites. Clinical Microbiology and Infection 2015;21:520

[14] Petney TN, Andrews RH. Multiparasite communities in animals and humans: frequency, structure and pathogenic significance. International journal for parasitology 1998;28:377.

[15] Berkman DS, Lescano AG, Gilman RH, Lopez SL, Black MM. Effects of stunting, diarrhoeal disease, and parasitic infection during infancy on cognition in late childhood: a follow-up study. The Lancet 2002;359:564.

[16] Ijaz MK, Rubino JR. Impact of infectious diseases on cognitive development in childhood and beyond: potential mitigational role of hygiene. Open Infectious Diseases Journal 2012;6:65.

[17] Halliez MC, Buret AG. Extra-intestinal and long term consequences of Giardia duodenalis infections. World journal of gastroenterology: WJG 2013; 19:8974.

[18] Oliveira D, Ferreira FS, Atouguia J, Fortes F, Guerra A, CentenoLima S. Infection by intestinal parasites, stunting and anemia in school-aged children from southern Angola. PLoS one 2015;10:e0137327.

[19] Hotez Hotez PJ, Alvarado M, Basáñez MG, Bolliger I, Bourne R, Boussinesq M, Brooker SJ, Brown AS, Buckle G, Budke CM, Carabin H. The global burden of disease study 2010: interpretation and implications for the neglected tropical diseases. PLoS neglected tropical diseases. 2014 Jul 24;8(7):e2865.

[20] Organization WH. The World health report 1996: fighting disease, fostering development: executive summary. Geneva: World Health Organization; 1996.

[21] Naghavi M, Wang H, Lozano R, Davis A, Liang X, Zhou M. GBD 2013 Mortality and Causes of Death Collaborators. Global, regional, and national age-sex specific all-cause and causespecific mortality for 240 causes of death, 1990-2013: a systematic analysis for the Global Burden of Disease Study 2013. Lancet 2015;385:117.

[22] Parija SC, Jeremiah S. Blastocystis: Taxonomy, biology and virulence. Tropical parasitology 2013;3:17.

[23] Roberts T, Stark D, Harkness J, Ellis J. Update on the pathogenic potential and treatment options for Blastocystis sp. Gut Pathogens 2014;6:17.

[24] Ajjampur SS, Tan KS. Pathogenic mechanisms in Blastocystis spp.-interpreting results from in vitro and in vivo studies. Parasitology international 2016;65:772.

[25] Fréalle E, El Safadi D, Cian A, Aubry E, Certad G, Osman M, et al. Acute Blastocystis-associated appendicular peritonitis in a child, Casablanca, Morocco. Emerging infectious diseases 2015;21:91.

[26] Chanu NO, Singh T, Dutta S. Occurrence of Intestinal Parasitic Infections with Gastrointestinal Symptoms in Children in Sikkim. International Journal of Scientific Research 2018;6.

[27] Duhok, Directorate for of Weather Forecasts Annual Report. 2018.

[28] Amin OM. Seasonal prevalence of intestinal parasites in the United States during 2000. The American journal of tropical medicine and hygiene 2002; 66:799.

[29] Al Saeed A, Issa S. Frequency of Giardia lamblia among children in Dohuk, northern Iraq. Eastern Mediterranean health journal, 2006; 12(5), 555-562.

[30] Ahmed, O. M. "Prevalence of intestinal parasites among food handlers and primary schoolchildren in Erbil Province, with initial cultivation of Entamoeba histolytica Schaudinn, 1903." PhD diss., Salahaddin University. Erbil; 2006.

[31] Hama A. Intestinal parasites in relation to malnutrition among primary school children in Erbil Province, with evaluation of some anti-parasitic drugs. PhD diss., council of the College of Science, Salahaddin University-Erbil; 2007.

[32] Hussein AH, Rashed SM, El-Hayawan IA, Aly NS, Ouf EA, Ali AT. Intestinal parasite infections and accuracy of direct thin and thick smear, formol-ether sedimentation, centrifugal flotation, and mini-FLOTAC techniques among patients with gastrointestinal tract disorders from the Greater Cairo region, Egypt. The American journal of tropical medicine and hygiene. 2017 Mar 8;96(3):589-94. 